\title{
Praise for Malignant
}

"An extraordinary work of disciplined observation and astonishing precision, Malignant reveals how the common course of cancer has worked its way into the American imaginary."

- Jonathan Simon, Adrian A. Kragen Professor of Law,

UC Berkeley School of Law

"In my nineteen years as a cancer survivor I have never read a book that was so spot-on when it comes to understanding the inadequacy of our current plan of attack in the war on cancer, which we have been fighting for over thirty years."

—Natalie Conforti, three-time young adult cancer survivor and advocate

"Lochlann Jain is the rare academic whose writing is as beautiful as her ideas." -Carl Elliott, author of White Coat, Black Hat: Adventures on the Dark Side of Medicine

"In this alternately galvanizing and moving report, Jain offers both a queer patient's-eye view and an astute scholar's analysis. Malignant extends the scholarship and activism surrounding HIV/AIDS to alert us that, in the case of cancer, ubiquity = death."

-Lisa Duggan, author of The Twilight of Equality?

Neoliberalism, Cultural Politics, and the Attack on Democracy

"As cancer increasingly becomes a metaphor for our lives, what do we do about the growing evidence of the role of the environment in cancer causation? Jain's complex and nuanced picture challenges the reader to dig down for our own conclusions. Malignant will be of enormous value." - Judy Norsigian, Executive Director, Our Bodies Ourselves

"Lochlann Jain offers a fresh and profound set of insights about the total social fact of cancer in the United States. Patients and cancer prevention advocates will benefit enormously from reading this fascinating book." —Richard Clapp, Professor Emeritus, Boston University School of Public Health

"How is it possible, S. Lochlann Jain asks in this moving, brutally honest book, for cancer to 'be inside so many people and remain outside society'? This searing exploration ... helps us understand why government, corporate, and military leaders are so reluctant to embrace cancer as a public issue and how their failure to do so affects our understanding of the disease." -Gerald Markowitz, coauthor of Deceit and Denial: The Deadly Politics of Industrial Pollution 
"Both extremely personal and highly analytic, Malignant offers an

idiosyncratic, irreverent, and probing mash-up of cancer in the U.S. today. The cancer that emerges is untidy, more a set of relationships than a thing. While highly critical of standard claims to authority and expert knowledge, suppressed politics, misplaced priorities, and victim blaming, Jain retains empathy and humor."

-Robert A. Aronowitz, author of Unnatural History:

Breast Cancer and American Society

"Jain takes an anthropologist's approach to exploring the intricacies of an experience on a shared cultural stage. This book brings new insights into the lived struggle of a patient, activist, and academic in understanding the full complexity of cancer."

-Karuna Jaggar, Executive Director, Breast Cancer Action

“Lochlann Jain's brilliant memoir/documentary offers us a thoroughly uncomfortable, provocative, and enticing read. We are led, step by meticulously researched step, into the abyss of the cancer culture, all the while being invited into the intimacy of Jain's own cancer story as a young adult. Malignant is a necessary read for our time, a remarkable achievement."

-Janie Brown, Executive Director, Callanish Society

"From the minute you start reading the first pages of this book, to the moment (hours later) when you arrive at its last pages, Lochlann Jain manages to grip you and hold you captive. The writing is marvelous, and the scholarship is incredible-but you aren't prepared for the disarming humor, or the delicate dissection of the psyche that Jain achieves. I could not stop reading this book. In the end, found myself enriched and wiser for it.”

-Siddhartha Mukherjee, author Emperor of All Maladies:

A Biography of Cancer (Pulitzer Prize winner)

"Malignant is a brilliant piece of medical anthropology, a beautifully poetic fusion of the personal and the political."

-Robert N. Proctor, author of Golden Holocaust:

Origins of the Cigarette Catastrophe and the Case for Abolition 
Malignant 
The publisher gratefully acknowledges the generous support of the General Endowment Fund of the University of California Press Foundation. 


\section{Malignant}

How Cancer Becomes Us

\section{S. Lochlann Jain}

甲ㅜ

UNIVERSITY OF CALIFORNIA PRESS

Berkeley · Los Angeles · London 
University of California Press, one of the most distinguished university presses in the United States, enriches lives around the world by advancing scholarship in the humanities, social sciences, and natural sciences. Its activities are supported by the UC Press Foundation and by philanthropic contributions from individuals and institutions. For more information, visit www.ucpress.edu.

University of California Press

Berkeley and Los Angeles, California

University of California Press, Ltd.

London, England

(C) 2013 by The Regents of the University of California

\section{Library of Congress Cataloging-in-Publication Data}

Jain, Sarah S. Lochlann, I967-

Malignant : how cancer becomes us / S. Lochlann Jain. pages $\mathrm{cm}$

Includes bibliographical references and index.

ISBN 978-0-520-27656-7 (hardback) — ISBN 978-0-52027657-4 (paper) — ISBN 978-0-520-95682-7 (ebook)

I. Cancer-Government policy-United States.

2. Cancer-Research-United States. 3. Cancer-Risk factors-Government policy-United States.

4. Carcinogens-Government policy-United States.

I. Title.

RC276.J35 $20 \mathrm{I} 3$

362.19699'4-dc23

2013018303

Manufactured in the United States of America

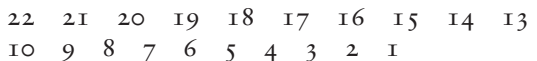

In keeping with a commitment to support environmentally responsible and sustainable printing practices, UC Press has printed this book on Rolland EnviroI00, a I00\% post-consumer fiber paper that is FSC certified, deinked, processed chlorine-free, and manufactured with renewable biogas energy. It is acid-free and EcoLogo certified. 
To my family:

Chosen, who let me in.

Blood, whom I would have chosen. 
This page intentionally left blank 